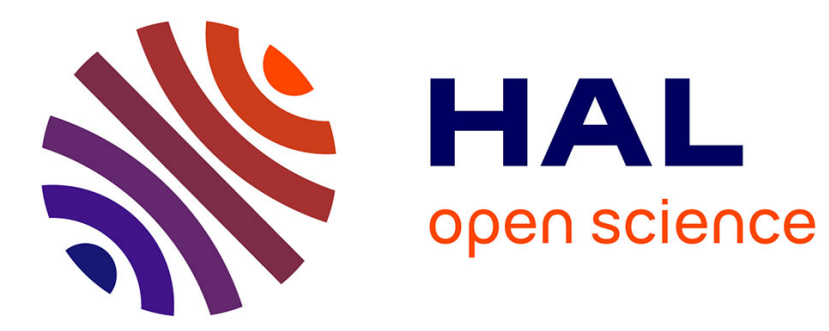

\title{
ELIMINATION OF DISLOCATIONS IN GaAs SINGLE CRYSTALS
}

M. Duseaux, C. Schiller, J. Cornier, Jérome Chevalier, J. Hallais

\section{To cite this version:}

M. Duseaux, C. Schiller, J. Cornier, Jérome Chevalier, J. Hallais. ELIMINATION OF DISLOCATIONS IN GaAs SINGLE CRYSTALS. Journal de Physique Colloques, 1983, 44 (C4), pp.C4-397-C4407. 10.1051/jphyscol:1983447 . jpa-00223067

\section{HAL Id: jpa-00223067 https://hal.science/jpa-00223067}

Submitted on 1 Jan 1983

HAL is a multi-disciplinary open access archive for the deposit and dissemination of scientific research documents, whether they are published or not. The documents may come from teaching and research institutions in France or abroad, or from public or private research centers.
L'archive ouverte pluridisciplinaire HAL, est destinée au dépôt et à la diffusion de documents scientifiques de niveau recherche, publiés ou non, émanant des établissements d'enseignement et de recherche français ou étrangers, des laboratoires publics ou privés. 


\section{ELIMINATION OF DISLOCATIONS IN GaAS SINGLE CRYSTALS}

M. Duseaux*, C. Schiller", J.P. Cornier*, J.P. Chevalier" " and J. Hallais* -Laboratoires d'blectronique et de Physique Appliqué, 3, avenue Descartes, 94450 Limeil-Brévannes, France

- C.N.R.S., Centre d'E'tudes de Chimie Métallurgique, 15, rue G. Urbain, 94400 Vitry-sur-Seine, France

Résumé - Pour plusieurs applications technologiques, des cristaux semiconducteurs de grande taille sont demandés. Divers types de défauts (ponctuels et étendus) sont présents dans ces cristaux. Dans le cas du GaAs, on sait que la présence de dislocations diminue fortement la durée de vie des lasers $\mathrm{Ca}_{1-x} \mathrm{Al}_{x} \mathrm{As}_{\mathrm{s}} / \mathrm{GaAs}$. De plus, de récentes études montrent que les propriétés électroniques des circuits intégrés au GaAs sont influencées par l'existence de dislocations. Leur présence dans les cristaux synthétisés par la méthode LEC (Liquid Encapsulated Czochralski) est essentiellement due aux contraintes thermiques existant pendant la croissance. Dans ce papier, nous présentons des résultats expérimentaux montrant qu'il est possible de réduire fortement (un facteur 10 au moins) la densité de dislocations, soit en diminuant le niveau de contraintes thermiques (technique Kyropoulos sous encapsulation liquide), soit en ajoutant des impuretés isoélectroniques (Indium) dans le bain liquide.

Abstract - Large size semiconduct or crystals are being requested in several device-oriented technologies. These crystals exhibit various defects (point and extended defects). Indeed, it is well-known in the case of GaAs that the presence of dislocations strongly decreases the life-time of Ga1- $x^{A l_{x} A s}$ / GaAs lasers. Moreover, it appears now, that the dislocations have a detrimental effect on GaAs integrated circuits. Their presence in LEC (Liquid Encapsulated Czochralski) crystals are mainly due to the thermal stresses occurring during the growth. We present in this paper some experimental results showing that it is possible to strongly reduce (by a factor 10, at least) the dislocation density either by decreasing the thermal stresses level (Liquid Encapsulated Kyropoulos Technique) or by adding an isoelectronic impurity (indium to the melt).

\section{INTRODUCTION}

Silicon is the most used semiconductor and it is routinely produced free of dislocations. Just behind silicon, gallium arsenide (GaAs) is the most popular III-V compound. However, dislocation free GaAs is not still available on the market since typical crystals exhibit $10^{4}-10^{5}$ dislocations per $\mathrm{cm}^{2}$. The influence of dislocations on electronic devices characteristics is more and more studied. Effectively, P.M. Petroff et al (1) have shown by a TEM study that the degradation rate of double heterostructure GaAlAs-GaAs lasers was due to the presence of dislocations. This fact is explained $/ 2,3 /$ by non-radiative recombination of minority carriers on the dislocations. The influence of dislocations on majority carriers devices (Field Effect Transistors for example is not so clear. The first work made in this field is reported by $R$. Zucca /4/ who did not establish clear correlation between the dislocation density and the FET fabrication yield. More recently, $Y$. Namishi et al /5,6/ measured drain-source current ( $\left.I_{D S}\right)$ and the threshold voltage ( $\left.V_{t h}\right)$ on 20 000 FET made on a GaAs wafer. They found that the most dislocated areas corresponded to high $I_{d s}$ values but low threshold voltage. They concluded that the 
elimination of dislocations was a very important problem. This conflicting remarks probably result from significant progress in the control of the device technology which allows now, like for the lasers, to point out the influence of the substrate defects. In this paper, we present our own results concerning the reduction of dislocation density in GaAs crystals and we shall study by transmission electron microscopy (TEM) and X-ray topography the defects, still present in the matrix.

\section{I - GaAs SINGLE CRYSTAL GROWTH AND DISLOCATIONS SOURCES}

The LEC (Liquid Encapsulated Czochralski) method is typically used to grow GaAs single crystals. The growth takes place in a high pressure chamber pressurized with argon, the melt being encapsulated with liquid boric oxide in order to minimize arsenic losses. The main advantages of this technique is the circular shape of the wafers and the homogeneity of impurities distribution across a slice. Depending upon the field of applications, the electrical properties of the crystal can be extremely important. One mostly uses either $\mathrm{n}^{+}$doped wafers $\left(10^{17}-10^{18} \mathrm{~cm}^{-3}\right)$ or semi-insulating ones (resistivity) $10^{8} \Omega, \mathrm{cm}$ ). However, the dislocation density is relatively high in such ingots $\left(10^{4}-10^{5} \mathrm{disl} / \mathrm{cm}^{2}\right)$, and their distribution is not uniform across a slice : the density is high in the centre and on the edges of the ingot, and reaches a minimum in an intermediate region

(W-shape) $/ 11 /$. This fact is well explained by thermoelastic calculations $/ 7-10 /$. Effectively, the presence of dislocations is mostly due to thermal stresses, occurring during the grawth (see fig. 1). Moreover, it has been shown that the stress level increases with the crystal diameter.
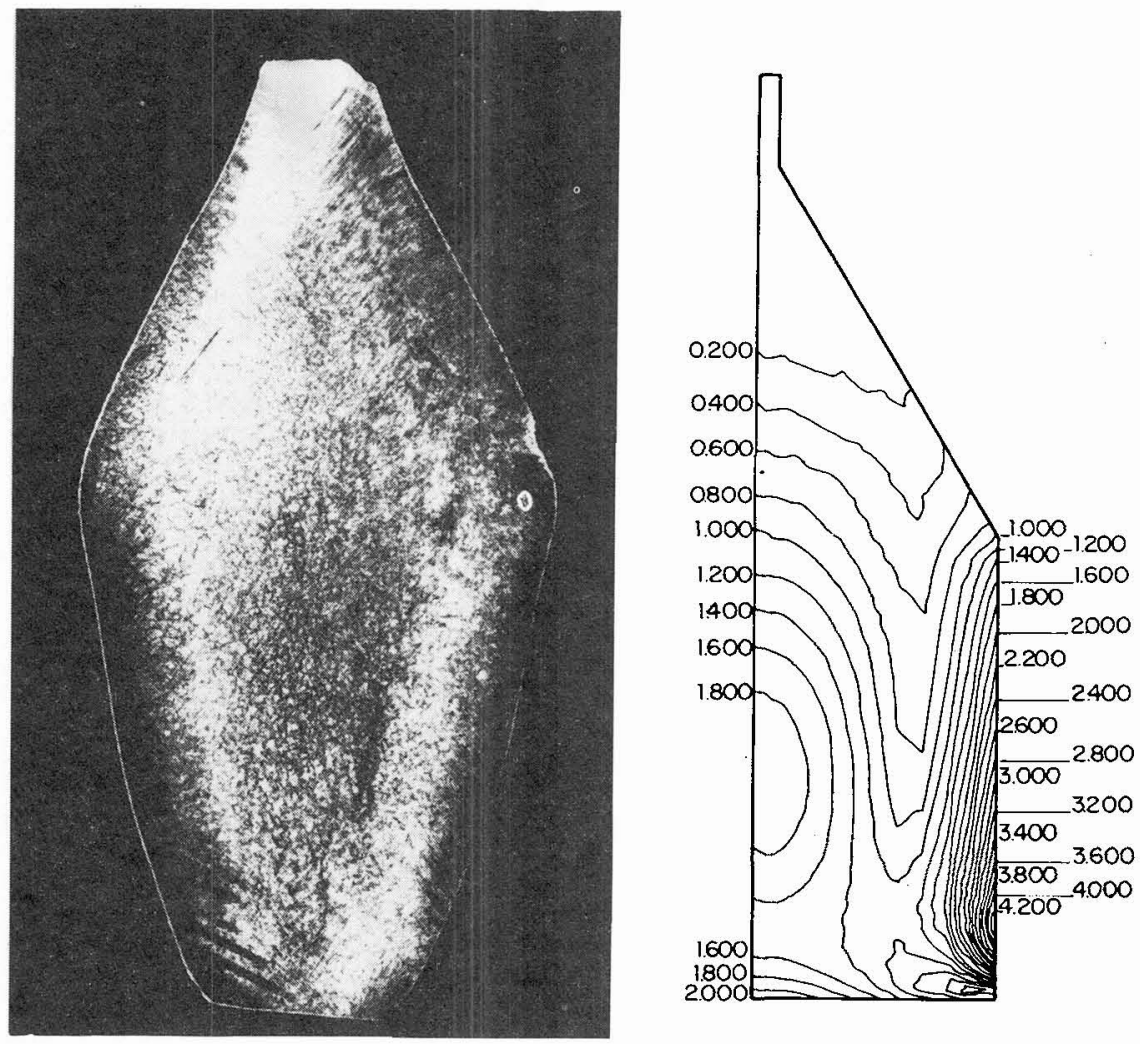

FIGURE 1 : X-ray topograph and isostresses $\left(\mathrm{kg} / \mathrm{mm}^{2}\right)$ map of a GaAs crystal 
In order to palliate this phenomena, three different techniques have been explored:

i) to start the growth from a dislocation-free seed : necking procedure /11-13/

ii) to imagine another crystal growth technique decreasing the thermal stresses : Liquid Encapsulated Kyropoulos (LEK) method /7,8,13,14/.

iii) to introduce impurities in the melt in order to increase the elastic limit of the crystal $/ 7,11,13-16 /$.

First and second tracks have largely been discussed in previous papers. We shall quickly have an overlook on the main results of these studies. Besides our last results concerning the last part will be developed.

\section{II - NECKING PROCEDURE}

Firstly reported by Dash /7/, this technique consists in pulling a small diameter crystal $(\leqslant 1 \mathrm{~mm})$. Due to the reduction of the diameter, the dislocations coming from the seed grow out of the crystal. The thermal st resses being too small, new dislocations cannot be introduced. After pulling $2-3 \mathrm{~cm}$, it is possible to obtain a dislocation-free crystal at the solid-liquid interface. Then, one can let the crystal diameter increase, and in some materials, the dislocations are not generated into the ingot since it needs a greater energy to generate dislocations from a dislocation-free seed than from a dislocated one.

This procedure has been successfully applied to silicon for many years, but in the case of GaAs, we have shown that it was not possible to obtain dislocation-free undoped material having a diameter larger than $15 \mathrm{~mm} / 7,11-13 /$ with this technique (see fig. 2). Moreover, we found that the critical resolved shear stress (CRSS), for a dislocation-free undoped crystal, strongly varjed (a factor ten at least) at high temperature from a crystal to another. We proposed /12/ that the nature and the mobility of native point defects were the main factors allowing these variations.

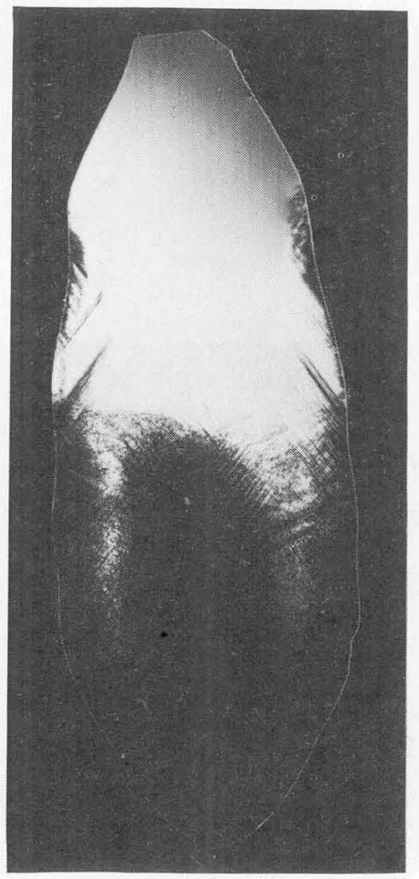

FIGURE 2 : X-ray topograph of a partially dislocation free undoped GaAs crystal. The diameter varies in the $15-20 \mathrm{~mm}$ range. 
This problem has been investigated by transmission electronic microscopy (TEM). Some small fringed defects $(\varnothing 50-100 \AA)$ have been observed in samples coming fromdislocation-free areas. Unfortunately, it is not yet possible to give an interpretation of the nature of these defects. However, their concentration corresponds to about $10^{18}$ at $/ \mathrm{cm}^{3}$, and it allows us to assume that their presence is due to native point defects agglomerates.

\section{III - LIQUID ENCAPSULAIED KYROPOULOS (LEK) TECHNIQUE}

In the case of the LEC technique, the thermoelastic calculations $/ 7,8$ / show that, the highest stresses are reached in the crystal at the boric oxide encapsulant-argon interface. It means that the ingot goes through the highest stress level when it leaves the encapsulant layer. In order to prevent this fact, a novel technique has been imagined /14/. In this technique, the crystal growth takes place under the $\mathrm{B}_{2} \mathrm{O}_{3}$ layer, and the ingot is not pulled during the growth. Thermoelastic calculations have also been made for this method $/ 7,8 /$, and they show that the stresses values are effectively smaller than in the case of the LEC geometry. Figure $3 a$ shows the isostress map of a $100 \mathrm{~mm}$ diameter GaAs crystal during the growth and figure $3 \mathrm{~b}$ presents an X-ray topograph of such an ingot. If we compare with the LEC geometry, it can be seen that the dislocation density has been decreased by a factor 10 $\left(10^{3}-10^{4}\right.$ dislocations $\left./ \mathrm{cm}^{2}\right)$. Moreover, the calculations show that the stress level does not depend on the diameter of the crystal in the LEK technique. Effectively, our experimental results on $35 \mathrm{~mm}$ diameter LEK crystals give about the same dislocation density $\left(10^{3}-10^{4} \mathrm{~cm}^{-2}\right)$.
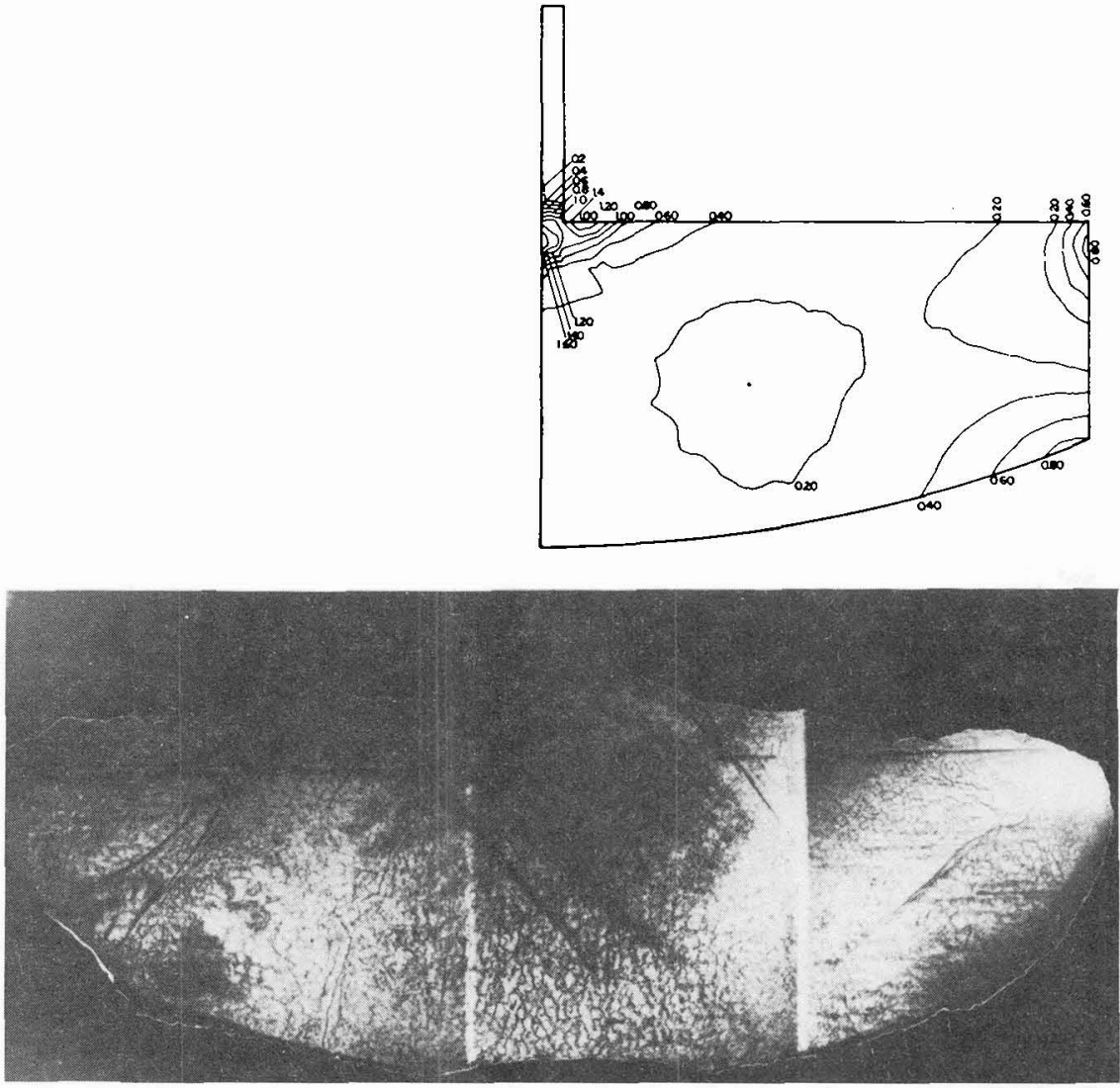

FIGUKE 3 : a) isost resses $\left(\mathrm{kg} / \mathrm{mm}^{2}\right)$ map of a $100 \mathrm{~mm}$ diameter GaAs crystal during LEK growth. b) X-ray topograph of the same crystal. 
So, this technique seems very interesting since we show that it was possible to obtain low dislocated GaAs single crystals exhibiting large diameter.

\section{IV - INFLUENCE OF THE DOPANTS}

It is well-known that in the case of GaAs, doping with group VI elements (S, Se, Te) strongly decreases the dislocation density /11/. Unfortunately, there are two main disadvantages to this technique :

1) The crystal is highly $\left(10^{18}-10^{19}\right.$ at $\left./ \mathrm{cm}^{3}\right) \mathrm{n}$-doped, and it is impossible to obtain, by this way, semi-insulating material.

2) The high concentration of impurities which is to introduce into the crystal and their low limit of solubility induce microprecipitates in the matrix.

In order to avoid these disadvantages, we have tried to dope the GaAs crystals with isoelectronic impurities $/ 7,13,15,16 /$ group III and group $V$ elements. The literature had already reported some results about the nitrogen doping /18/ ; and the indium and antimony doping /19/. A significant reduction of EPD (Etch Pits Density) had been obtained by this way for small (15-25 mm diameter) crystals. We have not detected any difference of the electrical properties between undoped and isoelectronic doped material. These results and the comparison with other data published in the literature $/ 20,21 /$ will be discussed elsewhere.

An open question concerning the isoelectronic doping was : does the high concentration of impurities $\left(10^{19}-10^{20}\right.$ at $\left./ \mathrm{cm}^{3}\right)$ in the crystal induce microprecipitates in the matrix, as in the case of group VI doping? In order to answer this question, a comparison between Tellurium (group VI) and Indium (group III) doped GaAs has been made by IEM. Moreover, X-ray topography of an In doped crystal will be discussed.

IV.1. - IEM study of Te doped GaAs crystal ( $2510^{18}$ at $\left./ \mathrm{cm}^{3}\right)$

Transmission electron microscopy of Te doped GaAs specimens shows numerous defects. Two classes of defects are observed : on the one hand, there is a low density of linear and planar defects and on the other hand, a relatively high density of defects, with contrast similar to dislocation loops (see figl:res 4 and 6 for example). These have sizes ranging from about $100 \AA$ to $800 \AA$ in diameter and with a density of about $10^{13}-10^{14} \mathrm{~cm}^{-3}$.

These observations lead us to make the following comments. The density of these loops-like defects is related to the presence of linear or planar defects. In both cases, we note that there is a high density of very small defects $(\sim 100 \AA)$ very close to the linear defect or in the plane of the stacking fault. In particular, for the latter, the small defects occur mainly on the stacking fault, with very few small ones outside, and with a normal density of large $(\sim 500 \AA)$ defects in the surrounding matrix. For the isolated dislocation, the observation shows a similar, but not identical state. Here, we observe very small defects very close to the dis location line (arrowed $A$ in $f i g .6)$. There are, however, large defects ( $\sim 600 \AA$ ) in a zone around the dislocation (distant up to a few thousand angstroms), and beyond this, there is a depletion zone. As far as the dislacation itself is concerned, there is a slight suggestion (arrowed B in fig. 6) of precipitation on the dislocation.

As far as all the defects with dislocation loop-like contrast are concerned, it is important to realize that in al] cases, this contrast is due to strain fields, but that the origin of the strain field may be diverse. Indeed, such contrast can be caused, not only by simple dislocation loops either of vacancy or interstitial nature, but also by misfit strains of coherent precipitates and also by dislocation loops surrounding incoherent precipitates. Furthermore, if the difference in structure factor between precipitate and matrix is slight, then there will be little additional contrast.

In weak-beam images ( $f$ ig. 5), the defects observed in the two-beam dark field inage (fig. 4) are almost always visible, with strong contrast. This contrast, for weak-beam conditions, is caused by strong distortion of the lattice and this can 


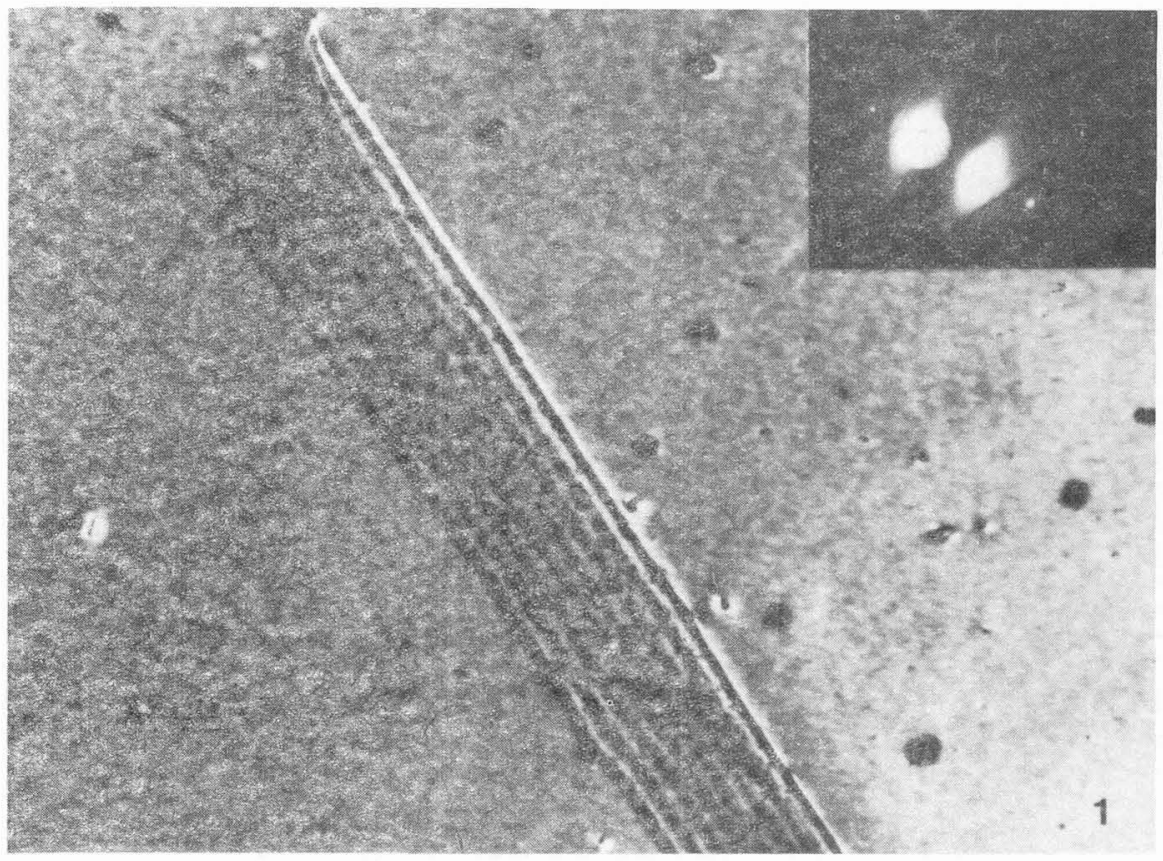

IGURE 4: Te doped GaAs, dark field with $g=\langle 220\rangle$

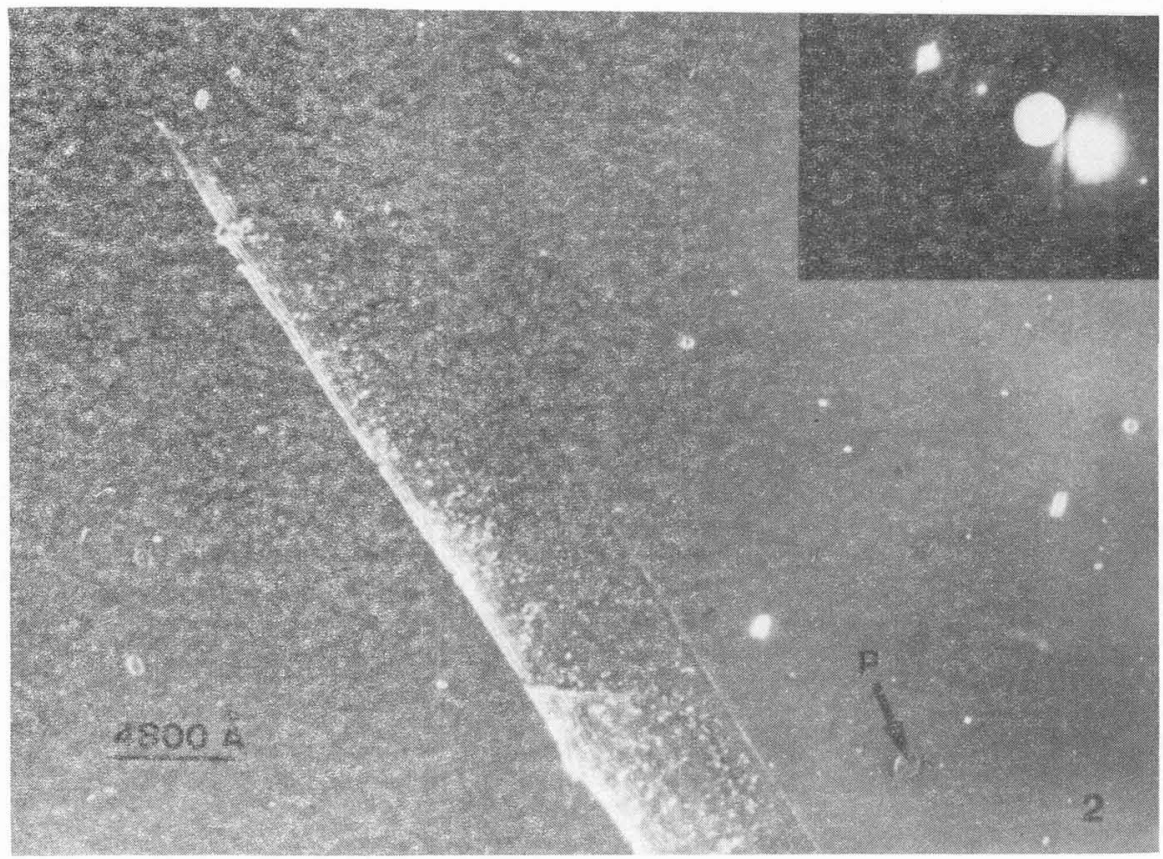

FIGURE 5 : Te doped GaAs, weak-beam with $g=\langle 220\rangle$ 


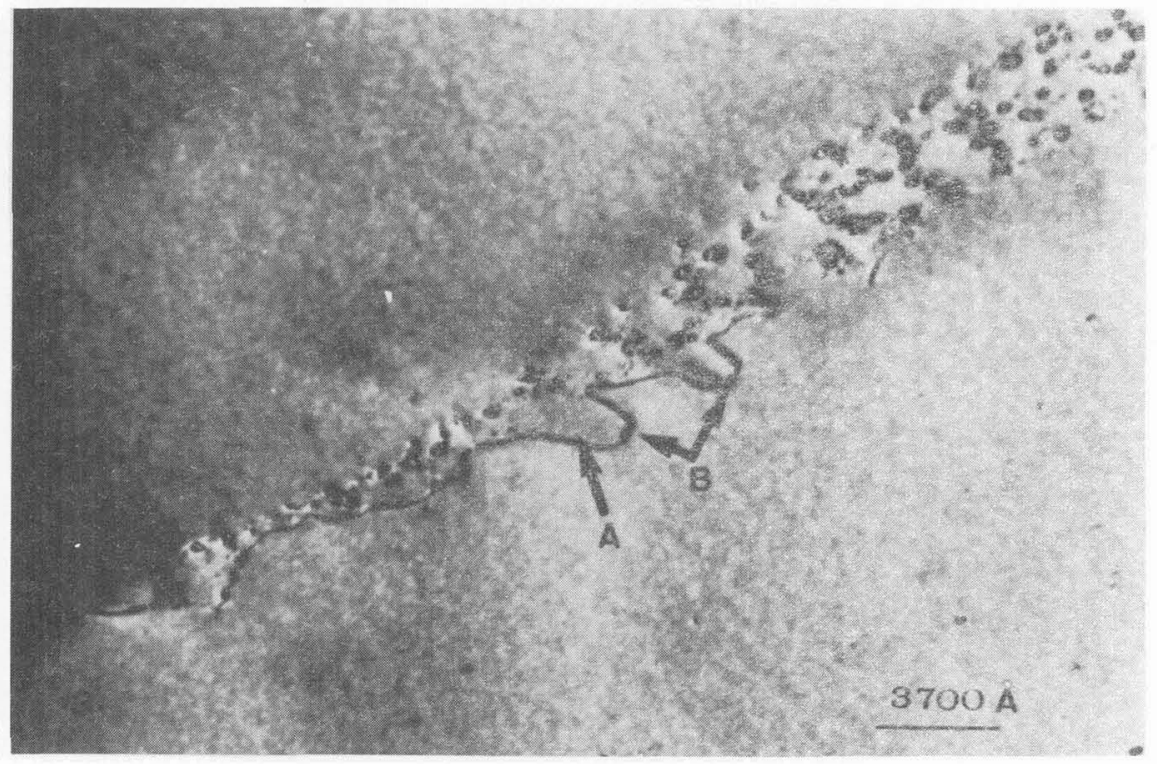

FIGURE 6 : Te doped GaAs, bright field with $g=\langle 220\rangle$.

only really be due to dislocations, virtually by definition. Thus, we can say that this contrast is caused by dislocation Ioops, although this nature, vacancy or interstitial, has not be ascertained in this study, and is still a matter of controversy in published work $/ 22,23 /$.

Furthermore, in the case of the large dislocation loops, there is an additional contrast inside the loop in the weak-beam image (arrowed $P$ in fig. 5). We believe that this could be due to precipitates. However, the precipitate density is too low to give rise to extra spots in the diffraction pattern, and hence it is neither possible to identify the structure of such precipitate or to produce dark-field images which would reveal them. Finally, we note that the largest dislocation loops have a tendency to become prismatic, with edges parallel to $\langle 110\rangle$ direction $/ 24 /$.

On the other hand, it is not possible to state definitely whether the smaller defects are associated with precipitates or not, but this can be considered as plausible.

IV.2. - IEM and X-ray topograph study of an In-doped GaAs crystal ( $10^{20}$ at $\left./ \mathrm{cm}^{3}\right)$

Lattice defects have been detected by different techniques. X-ray transmission topography using a classical Lang camera (microfocus $0.1 \mathrm{~mm}$ ) has been performed with MoK $\alpha_{1}$ radiation on wafers cut in each ingot through the (001) symmetry axis and polished down to $0.2 \mathrm{~mm}$ with $\{110\}$ and $\{111\}$ diffraction vectors. 
The $x$-ray transverse topograph presented on fig. 7 was obtained on a (110) plate cut along the growth axis. The crystal diameter is $20 \mathrm{~mm}$. Apart from linear defects lying along the (001) direction with a very low density ( $<510^{2} \mathrm{~cm}^{-2}$ ), we observed defects located at the periphery of the crystal within $2 \mathrm{~mm}$; on each type of defects, the contrast of the image (black, white or grey) is related to their location near the entrance surface (white or dynamic image) or near the exit surface (black or cinematic image).

The defects lie in $\{111\}$ glide plane and a cathodoluminescence image obtained in scaning electron microscopy is shown in fig. 8. These crystallographic defects have tridimensional structures and are not related to dislocations but rather to precipitates. Their density here in the range of $10^{4} \mathrm{~cm}^{-2}$ appears to be too low to be observed by TEM.

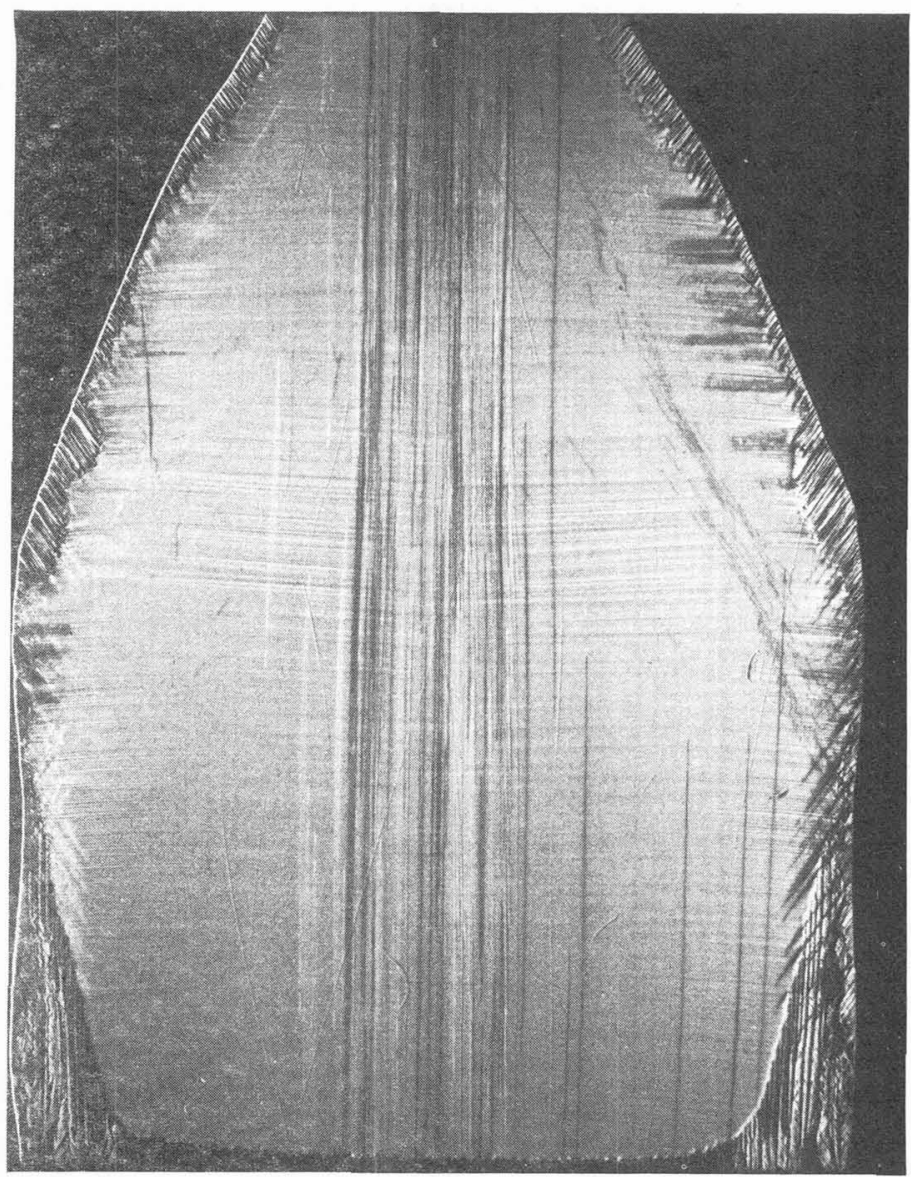

FIGURE 7 : X-ray topograph of a In-doped GaAs crystal ( $20 \mathrm{~mm}$ ). 

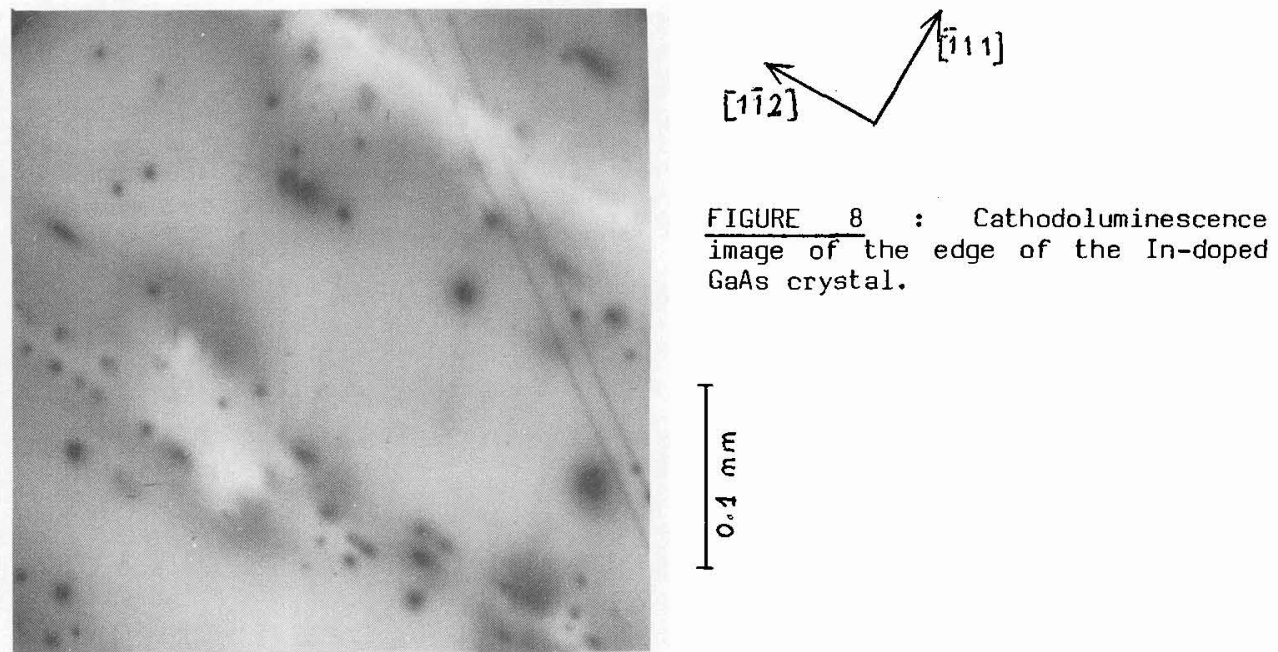

However, it was interesting to know if smaller micro-defects were visible in the matrix. Carefull transmission electron microscopy studies show that there is no contrast which can be associated to either dislocation loops or coherent precipitates (see fig. 9).

At this time, the greater low dislocated crystal $\left(10^{2}-10^{3} \mathrm{~cm}^{-2}\right)$ doped with in is about $40 \mathrm{~mm}$ diameter.

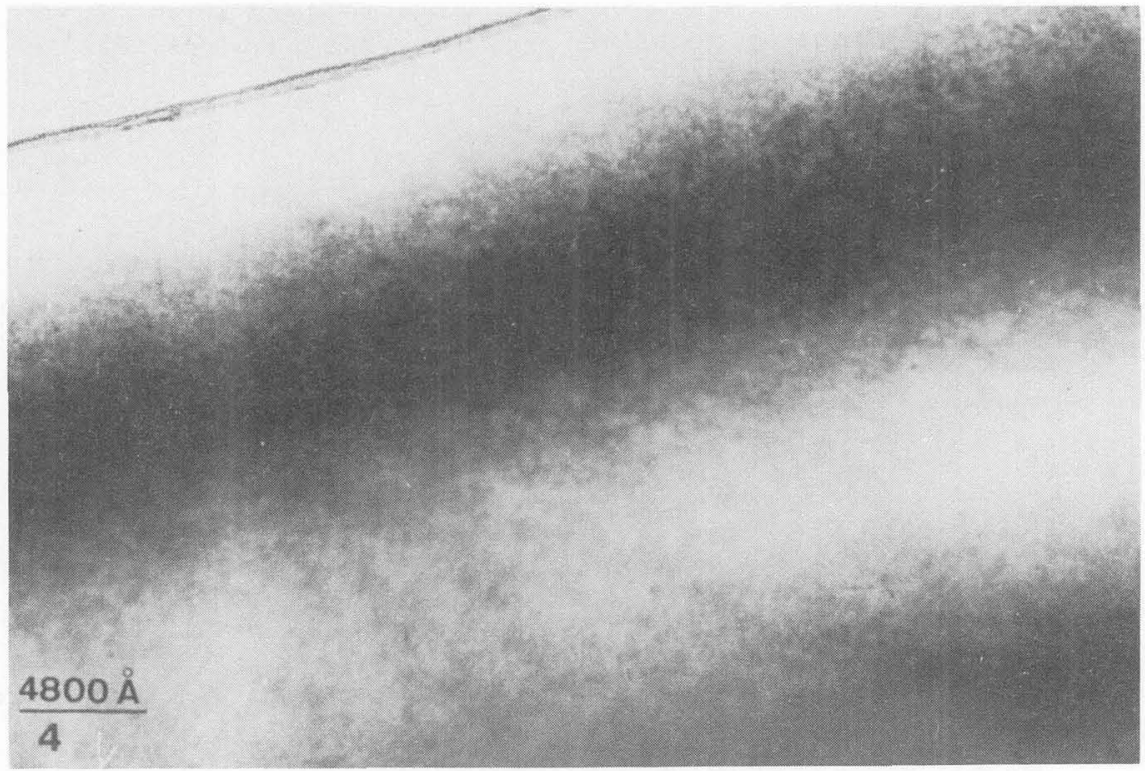

FIGURE 9 : In-doped GaAs, bright field with $g=\langle 220\rangle$. 


\section{CONCLUSION}

In order to decrease the dislocation density in GaAs crystals, we have investigated three kinds of techniques. We showed that the necking procedure did not allow to obtain undoped dislocation-free crystals if its diameter was greater than $15-20 \mathrm{~mm}$. Un the other hand, the LEK technique has permitted to synthesize low dislocated (in the $10^{3}-10^{4} \mathrm{~cm}^{-2}$ range) large crystals ( $\sim 10 \mathrm{~cm}$ diameter). This result is very promising since the dislocation density is ten times higher in the case of typical available GaAs. Finally, we made different studies on isoelectronic doped material and we showed that it was possible to obtain semi-insulating GaAs having very low dislocation density (in the $10^{2}-10^{3} \mathrm{~cm}^{-2}$ range).

\section{ACKNOMLEDGMNTS}

This work has been supported by DESTI (Contract $n^{\prime \prime} 82$ A 1220). We thank Ur. P.J. Koksnoer for the growth of the In-doped crystal presented on fig. 7.

\section{REFERENCES}

(1) P.M. PETROFF, R.L. haRTMAn, Appl. Phys. Letters, 23(8) (1973) 469.

(2) H. KRESSEL, J.K. BUTLER, Semiconduct or lasers and heterojunct ion LEDS, Quantum electronics, Academic Press, New-York (1977) 533.

(3) H.C. CASEY Jr, M.B. PANISH, Heterostructure Lasers - Part B Quantum Electronics - Academic Press, New-York (1978) 277.

(4) R. ZUCCA, B.M. WELCH, P.M. ASBECK, R.C. EDEN, S.I. LONG, Semi-insulating III-V Materials, Nott ingham (1980) 335.

(5) Y. NAMISHI, S. ISHIDA, T. HONDA, H. YAMASAKI, S. MIYAZAWA, Jap. J. Of Appl. Physics, 21 (6) (1982) 335.

(6) Y. NAMISHi, S. ISHIDA, S. MIYAZAMA, Jap. J. of Appl. Physics, 22 (1) (1983) 54.

(7) M. DUSEAUX, Thesis, Paris (1982).

(8) M. DUSEAUX, to be published in J. of Cryst. Growth (1983).

(9) A.S. JORUAN, R. CARUSO, A.R. VON NEIDA, Bell System Tech. Journal, 59 (1980) 593.

(10) M. UUSEAUX, G. JACOB, European Meeting on Crystal Growth, Prague (1982).

(11) G. JACOB, J.P. FARGES, C. SCHEMAL I, M. DUSEAUX, J. HALLAIS, W.J. BARTELS, P.J. RUKSNOER, J. of Cryst. Growth, 57 (1982) 245.

(12) M. DUSEAUX, G. JACOB, Appl. Phys. Lett., 40 (9) (1982) 790.

(13) G. JACUB, Proc. of the Semi-Insulating III-V Materials Conf., Evian (1982) 2.

(14) G. JACOB, J. of Cryst. Growth, 58 (1982) 455.

(15) G. JACOB, M. DUSEAUX, J.P. FARGES, to be published in J. of Cryst. Growth (1983).

(16) G. JACOB, J. of Cryst. Growth, 59 (1982) 669. 
(17) W.C. DASH, Growth and Perfection of crystals, Ed. R.M. Doremus, B.W. Roberts and D. Turbull, Wiley (1958) 361.

(18) Y. SEKI, H. WATANABE, J. Matsui, J. Appl. Physics, 49 (2) (1978) 822.

(19) M.L. MIL 'VIUSKII, V.B. OSVENSKII, S.S. SHIFRIN, J. of Cryst. Growth, 52 (1981) 396.

(20) E.V. SOLOV'EVA, N.S. RYTOVA, M.G. MIL'VIDSKII and N.V. GANINA, Sov. Phys. Semicond. 15 (11) (1981) 1243.

(21) E.V. SOLOV'EVA, M.G. MIL'VIDSKII, V.B. OSVENSKII, YU. N. BOL 'SHEVA, YU A. GRIGOK'EV, V.P. TSYGANOV, Sov. Phys. Semicond., 16 (3) (1982) 366.

(22) P.W. HUTChinSON, P.5. DOBSON, Phil. Mag. 30 (1974) 65.

(23) D. LAISTER, G.M. JENkINS, Phil. Mag. 23 (1971) 1077.

(24) B. Hugues, G.H. Narayanan, Phys. Stat. Sol. (a) 46 (1978) 627. 